11. S. LeVay, M. P. Stryker, C. J. Shatz, J. Comp. Neu rol. 179, 223 (1978); A. Antonini and M. P. Stryker, J. Neurosci. 13, 3549 (1993).

12. A. Kirkwood, S. M. Dudek, J. T. Gold, C. D. Aizen man, M. F. Bear, Science 260, 1518 (1993); A. Kirk wood and M. F. Bear, J. Neurosci. 14, 3404 (1994); A. Kirkwood, H.-K. Lee, M. F. Bear, Nature 375, 328 (1995).

13. U. Dräger, J. Neurophysiol. 41, 28 (1978); M. Fagiolini et al., Vision Res. 34, 709 (1994). J. A. Gordon and M. P. Stryker [J. Neurosci., in press] show that ocular dominance plasticity in mouse primary visual cortex is subject to the same conditions and occurs in the same way as in the cat, involving both intracortical and thalamocortical changes (1).

14. Recordings were obtained from layer II/III in the binocular zone of $400-\mu \mathrm{m}$-thick coronal slices of mouse primary visual cortex (C57/BL6; <6 weeks old) continuously superfused with oxygenated $\left(95 \% \mathrm{O}_{2}, 5 \%\right.$ $\mathrm{CO}_{2}$ ) artificial cerebrospinal fluid (ACSF), containing (in millimolar) $119 \mathrm{NaCl}, 2.5 \mathrm{KCl}, 1.3 \mathrm{MgSO}_{4}, 1.0$ $\mathrm{NaH}_{2} \mathrm{PO}_{4}, 26.2 \mathrm{NaHCO}_{3}, 2.5 \mathrm{CaCl}_{2}$, and 11 glucose. Extracellular pipettes (1 M NaCl, 1-3 megohm) monitored stable, half-maximal baseline field potentials evoked from layer IV by a bipolar Pt-Ir electrode delivering $100-\mu$ s pulses at $0.1 \mathrm{~Hz}$. Five episodes of TBS were given at 10-s intervals to induce LTP before depotentiation was attempted with 900 pulses at 1 $\mathrm{Hz}$. A single TBS consisted of 10 repetitions of four stimuli at $100 \mathrm{~Hz}$ delivered at $200-m s$ intervals (12). All experiments were terminated by bath application of 10 MM 6-cyano-7-nitroquinoxaline-2,3-dione (CNQX, Tocris, UK) and $50 \mu \mathrm{M} \mathrm{D}$-(-)-2-amino-5-phosphonovaleric acid (D-APV, Sigma) to determine the synaptic component of the field response. Similar results were obtained by measurements of synaptic slope or peak amplitude normalized to the baseline period before TBS, and renormalized to the 10 min preceding $1-\mathrm{Hz}$ stimulation to adjust for variable elapsed time postTBS across experiments. Both LTP and depotentiation wele prevented by the $N$-methyl-D-aspartate receptor antagonist APV, as also reported for LTD of naïve synapses (12). R,S- $\alpha-M C P G$ or (+)-MCPG (Tocris) were dissolved in $100 \mathrm{mM} \mathrm{NaOH}$ at $50 \mathrm{mM}$, then diluted to $500 \mu \mathrm{M}$ in ACSF.

15. K. R. Stratton, P. F. Worley, J. M. Baraban, Eur. J. Pharmacol. 186, 357 (1990); S. Charpak, B. H. Gähwiler, K. Q. Do, T. Knöpfel, Nature 347, 765 (1990) R. W. Gereau and P. J. Conn, J. Neurophysiol. 74 122 (1995); A. Baskys, Trends Neurosci. 15, 92 (1992).

16. In visual cortical slices prepared and maintained as de-


membrane potential of regular-spiking supragranular pyramidal cells [D. A. McCormick et al., J. Neurophysiol. 54,782 (1985)] from -50 to $+40 \mathrm{mV}$ for $100 \mathrm{~ms}$ in the whole-cell voltage-clamp mode (Axoclamp-2B). The pipette solution contained (in millimolar): 122.5 potassium gluconate, $17.5 \mathrm{KCl}, 10$ Hepes buffer, 0.2 EGTA, 8 $\mathrm{NaCl}, 2.0 \mathrm{Mg}$-adenosine $5^{\prime}$-triphosphate, and $0.3 \mathrm{Na}_{3}$ guanosine $5^{\prime}$-triphosphate ( 3 to 8 megohm, pH 7.2 290 to $300 \mathrm{mOsm}$ ). t-ACPD (Tocris) was dissolved in ACSF and bath applied.

17. In vivo experiments were done as described $[\mathrm{H}$. O Reiter, D. M. Waitzman, M. P. Stryker, Exp. Brain Res. 65, 182 (1986)]. Infusion cannulae connected to osmotic minipumps (Alza model 2002) were implanted bilaterally into postnatal day 28 (P28) kitten striate cortex under sterile conditions. One eyelid was sutured shut under brief halothane anesthesia on P30, and $M D$ was verified for 5 days. $R, S-\alpha-$ or $(+)-M C P G$ (25 to $50 \mathrm{mM}$ in $100 \mathrm{mM} \mathrm{NaOH})$, or vehicle $(100 \mathrm{mM}$ $\mathrm{NaOH}, \mathrm{pH} 10)$ solution was delivered at a constant rate $(0.5 \mu \mathrm{l} /$ hour $)$ throughout the experiment. In some cases, MCPG solutions were first neutralized to physiological $\mathrm{pH} 7$, which rendered the drug inactive on the in vitro /AHP assay (16). On P35, animals were prepared for acute single-unit recording by standard techniques in accordance with University of California, San Francisco, guidelines for anima care. In brief, kittens were anesthetized and main tained with a combination of barbiturate infusion [pentobarbital sodium (Nembutal) $10 \mathrm{mg} / \mathrm{kg}$ intravenous] and $\mathrm{N}_{2} \mathrm{O}: \mathrm{O}_{2}(2: 1)$ ventilation. Extracellular unit recordings were obtained immediately in front and no further than $1.5 \mathrm{~mm}$ from each cannula with resin- coated tungsten microelectrodes ( 1 to 3 megohms) in vertical penetrations spaced evenly at $400-\mu \mathrm{m}$ intervals along the medial bank. Electrode tracks were reconstructed in Nissl-stained coronal sections to confirm sampling from all layers of visual cortex Light bar stimuli were swept across the receptive field with a hand-held lamp to assign each cell to an ocular dominance group on the basis of Hubel and Wiesel's seven-point scale (1). Here, an ocular dominance of 7 represents complete dominance by the open eye. The contralateral bias index (CBI), a weighted average of the bias toward one eye or the other, was calculated for each treated hemisphere, separately and as a group, according to the formula: $\mathrm{CBI}=\left[\left(n_{1}-n_{7}\right)+2 / 3\left(n_{2}-n_{6}\right)+1 / 3\left(n_{3}-n_{5}\right)+\right.$ $N] /(2 N)$, where $N$ is the total number of cells and $n_{x}$ is the number within ocular dominance group $x$.

18. In each hemisphere, multibarreled iontophoretic pipettes were lowered into striate cortex just beyond the most distant penetration site used for determination of ocular dominance $(<2 \mathrm{~mm}$ from cannula) Activation thresholds for kainic acid and t-ACPD (both $20 \mathrm{mM}$ in saline) were determined by gradually increasing iontophoretic ejection currents (WP model 160) in 20-nA steps once every $60 \mathrm{~s}$. Each round of iontophoresis was preceded by isolation of multiple units with visual stimulation and concluded by verifying the presence of the same visually driven cells. Additional iontophoretic penetrations amidst the single-unit sites and well beyond ( $>3 \mathrm{~mm}$ ) confirmed that all shifted cells lay within a region in which mGluRs were blocked.

19. K. Lingenhöhl, H.-R. Olpe, N. Bendali, T. Knöpfel, Neurosci. Res. 18, 229 (1993); P. M. B. Cahusac, Eur. J. Neurosci. 6, 1505 (1994); D. E. Jane et al. Neuropharmacology 32, 725 (1993).

20. A. Antonini and M. P. Stryker, Science 260, 1819 (1993).

21. J. Comp. Neurol., in press

22. C. R. Olson and R. D. Freeman, J. Neurophysiol. 38 26 (1975); C. Blakemore, M. J. Hawken, R. F. Mark
J. Physiol. (London) 327, 489 (1982); L. Mioche and W. Singer, J. Neurophysiol. 62, 185 (1989); T. K. Hensch et al., Soc. Neurosci. Abstr. 21, 795.4 (1995).

23. S. Nakanishi and M. Masu, Annu. Rev. Biophys. Biomol. Struct. 23, 319 (1994); J.-P. Pin and R. Duvoisin, Neuropharmacology 34, 1 (1995).

24. Y. Hayashi et al., J. Neurosci. 14, 3370 (1994); C Thomsen, E. Boel, P. D. Suzdak, Eur. J. Pharmacol. 267, 77 (1994).

25. E. F. Birse et al., Neuroscience 52, 481 (1993); S. A Eaton et al., Eur. J. Pharmacol. 244, 195 (1993).

26. J. A. Saugstad, T. P. Segerson, G. L. Westbrook, Eur. J. Pharmacol. 289, 395 (1995).

27. Although C. Joly et al. [J. Neurosci. 15, 3970 (1995)] suggest, contrary to (26), that racemic R,S-MCPG is not an effective antagonist at mGluR5 splice variants compared with mGluR1, the same laboratory has shown the stereoselective isomer (+)-MCPG to block all known group I mGluRs [I. Brabet et al., Neuropharmacology 34, 895 (1995)], consistent with (26).

28. D. E. Jane et al., Br. J. Pharmacol. 112, 809 (1994); O. J. Manzoni, P. E. Castillo, R. A. Nicoll, Neuropharmacology 34, 965 (1995). Only presynaptic mGluR4 is not blocked by MCPG in vitro (24).

29. O. Manzoni, M. G. Weisskopf, R. A. Nicoll, Eur. J Neurosci. 6, 1050 (1994); P. Chinestra, L. Anikstejn D. Diabira, Y. Ben-Ari, J. Neurophysiol. 70, 2684 (1993); A. Y. Hsia et al., Neuropharmacology 34, 1567 (1995).

30. Z. A. Bortolotto, Z. I. Bashir, C. H. Davies, G. L. Collingridge, Nature 368, 740 (1994).

31. We thank S. Harris for assistance during the implant surgeries, and M. Fagiolini and R. A. Nicoll for critical comments on the manuscript. T.K.H. is a Howard Hughes Medical Institute Predoctoral Fellow. Supported by grants to M.P.S. from the National Institutes of Health (EY02874) and the Human Frontiers Science Program (RG69/93).

3 October 1995; accepted 30 January 1996

\title{
Transcription-Coupled Repair Deficiency and Mutations in Human Mismatch Repair Genes
}

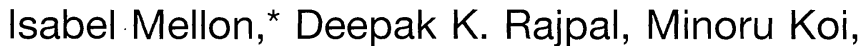 \\ C. Richard Boland, Gregory N. Champe
}

Deficiencies in mismatch repair have been linked to a common cancer predisposition syndrome in humans, hereditary nonpolyposis colorectal cancer (HNPCC), and a subset of sporadic cancers. Here, several mismatch repair-deficient tumor cell lines and HNPCC-derived lymphoblastoid cell lines were found to be deficient in an additional DNA repair process termed transcription-coupled repair (TCR). The TCR defect was corrected in a mutant cell line whose mismatch repair deficiency had been corrected by chromosome transfer. Thus, the connection between excision repair and mismatch repair previously described in Escherichia coli extends to humans. These results imply that deficiencies in TCR and exposure to carcinogens present in the environment may contribute to the etiology of tumors associated with genetic defects in mismatch repair.

Nucleotide excision repair helps cells tolerate exposure to various DNA-damaging agents present in the environment by re-

I. Mellon, D. K. Rajpal, G. N. Champe, Department of Pathology, Program in Toxicology, Markey Cancer Center, University of Kentucky, Lexington, KY 40536, USA. M. Koi, Laboratory of Molecular Carcinogenesis, National Institute of Environmental Health Sciences, Post Office Box 12233, Research Triangle Park, NC 27706, USA. C. R. Boland, Department of Medicine, University of California, San Diego, 9500 Gilman Drive, La Jolla, CA 92093-0688, USA.

*To whom correspondence should be addressed. moving helix-distorting lesions from cellular genomes. The general strategy appears to be similar in organisms ranging from Escherichia coli to humans. This process is complex and requires the participation of a number of different proteins (1). Its role in ameliorating the carcinogenic consequences of DNA damage has been inferred from studies of the genetic disease xeroderma pigmentosum (XP). Cells from XP patients are hypersensitive to the killing and mutagenic effects of ultraviolet light (UV) and 
are defective in the excision repair of their DNA. Nucleotide excision repair can be coupled to transcription. In normal human cells (2), E. coli (3), and Saccharomyces cerevisiae (4), UV-induced cyclobutane pyrimidine dimers are removed more rapidly from the transcribed strands than from the nontranscribed strands of active genes. This feature of repair is generally termed transcription-coupled repair (here, referred to as TCR) (5).

We have shown that mutations in two genes required for DNA mismatch repair, mutS and mutL, abolish TCR of UV photoproducts from the lac operon in E. coli (6). In contrast to nucleotide excision repair, mismatch repair corrects single-base mismatches and small insertion or deletion mispairs that can be generated during replication (7). Our results indicate an association between mismatch repair and nucleotide excision repair in E. coli and may implicate components of mismatch repair in the coupling of excision repair to transcription.

In addition, this link could have important implications for human disease. Mutations in the human homologs of the $E$. coli mismatch repair genes mutS and mutL (hMSH2, hMLH1, and hPMS2) are associated with $\operatorname{HNPCC}(8,9)$. This disease is one of the most common cancer predisposition syndromes and exhibits an autosomal dominant mode of inheritance. Patients are at risk for early onset of colon cancer (Lynch syndrome I) or early onset of colon cancer with tumors at additional sites, including the stomach, small intestine, kidney, ureter, and ovary (Lynch syndrome II) $(10,11)$. Normal cells from affected individuals are heterozygous, with a germline mutation in one of four mismatch repair genes ( $h \mathrm{MSH} 2, h \mathrm{MLH} 1, h P M S 1$, or hPMS2) $(8,9)$. Tumor cells from affected individuals have mutations in both alleles of a mismatch repair gene, and the inactivation of the second allele occurs as a consequence of a somatic mutation or a reduction to homozygosity.

In addition, mutations in $h M S H 2$, $h M L H 1$, and $h P M S 2$ have been identified in sporadic tumor cell lines derived from the colon and endometrium (12-16). In general, both sporadic and HNPCC tumor cells with genetic defects in mismatch repair exhibit elevated spontaneous mutation rates in microsatellite sequences, and several sporadic tumor cell lines have been found to be deficient in the processing of singlebase mismatches and small insertion or deletion mispairs $(12,13,16)$. To determine whether mutations in human mismatch repair genes also affect the removal of environmentally induced DNA damage, we examined here TCR in a collection of tumorand HNPCC-derived lymphoblastoid cell lines.
We measured the removal of cyclobutane pyrimidine dimers from individual strands of the gene encoding dihydrofolate reductase (DHFR) in UV-irradiated cells. Using strand-specific RNA probes, we examined repair in a 20-kb Kpn I restriction fragment that resides within the transcription unit of the $\sim 30-k b$ gene. Cells were irradiated with UV light $\left(10 \mathrm{~J} / \mathrm{m}^{2}\right)$ and either lysed immediately to determine the initial frequency of pyrimidine dimers ( $\sim 1.5$ to 2 in each strand of the fragment) or incubated for increasing periods of time to allow repair and then lysed. Large molecular mass DNA was purified and treated with restriction enzymes. Two portions of each DNA sample were analyzed: one was treated with $\mathrm{T} 4$ endonuclease $\mathrm{V}$ to produce a single-strand DNA break at each cyclobutane pyrimidine dimer and the other was mock-treated. Samples were subjected to electrophoresis under denaturing conditions and then transferred to a membrane. The membranes were then sequentially hybridized with strand-specific RNA probes to quantify the abundance of full-length restriction fragments for each strand at each time point.

As repair occurred, fewer T4 endonuclease-sensitive sites remained in the DNA, resulting in fewer strand breaks produced by the endonuclease and more full-length fragments appearing in the enzyme-treated sample. We determined the extent of repair by calculating (using the Poisson expression) the average number of dimers per strand at each time point from the ratio of full-length restriction fragments in the enzyme-treated and untreated samples.

We first examined the mismatch repairproficient colon tumor cell line SW480 (12). As in our previous observations of a human cell line (2), here pyrimidine dimers were rapidly removed from the transcribed strand of the gene encoding DHFR, whereas repair in the nontranscribed strand was slower (Fig. 1). Comparison of the enzymetreated samples probed for the two different strands revealed more full-length fragments for the transcribed strand than for the nontranscribed strand. Quantitation of data obtained from several autoradiograms showed that within 3 hours after UV treatment, almost $50 \%$ of the dimers were removed from the transcribed strand, whereas only $20 \%$ were removed from the nontranscribed strand. This difference in the amount of repair was also observed 6 and 9 hours after exposure to UV. However, repair in both strands approached completion within 20 hours after exposure to UV. Similar results were obtained for the mismatch repair-proficient endometrial tumor cell line KLE $(16,17)$.

We next examined TCR in several sporadic tumor cell lines that exhibit microsat-



Fig. 1. TCR in human sporadic colon and endometrial tumor cell lines. Repair was measured and DNA samples were taken at the times indicated at the top of the lanes. Strand-specific RNA probes were made with the use of pGEM0.69EH (34) as a template. Open symbols represent the transcribed strand, and closed symbols represent the nontranscribed strand. Each value plotted represents data averaged from at least two independent biological experiments and at least four autoradiograms. Treatment or no treatment with T4 endonuclease $\mathrm{V}$ is indicated by "+" and "-,", respectively; T, transcribed strand; NT, nontranscribed strand.

ellite instability, have mutations in mismatch repair genes, and are defective in the repair of DNA-containing mismatches. The LoVo cell line, which arises from a colon tumor, has deletions in both alleles of hMSH2 (13); HEC59 is an endometrial tumor cell line with mutations in both alleles of $h \mathrm{MSH} 2(13,18)$; and HEC $1 \mathrm{~A}$ is an endometrial tumor cell line containing a nonsense codon in the hPMS2 gene and no detectable wild-type $h P M S 2$ transcript (16).

Examination of representative autoradiograms revealed that there was no significant difference in the repair of the transcribed and nontranscribed strands of the gene encoding DHFR in all three mutant cell lines (Fig. 1). The kinetics and extent of repair were determined by averaging results from several experiments. In each mutant cell line, repair rates in the transcribed and nontranscribed strands of the gene were similar. In LoVo cells, there also appeared to be some slowing of repair in both strands relative to the nontranscribed strand of the repair-proficient SW480 cell line. In HEC59 


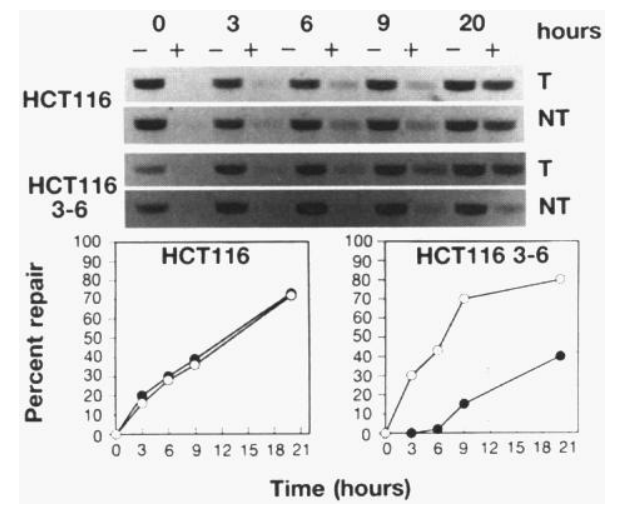

Fig. 2. Restoration of TCR by chromosome 3 transfer. Repair was assayed as described in Fig. 1. The cell line with chromosome 3 transfer, HCT116 3-6, was derived from HCT116 by microcell fusion (20). Open symbols represent the transcribed strand, and closed symbols represent the nontranscribed strand. Treatment in lanes was as described in Fig. 1.



Fig. 3. UV sensitivity of tumor cell lines. Cells were plated in duplicate in 60 - or $100-\mathrm{mm}$ dishes at densities of $1 \times 10^{2}$ to $1 \times 10^{3}$ cells per dish, incubated for 24 hours, and irradiated with UV doses ranging from 0 to $20 \mathrm{~J} / \mathrm{m}^{2}$. Cells were grown until colonies were visible ( $\sim 1$ week), stained with crystal violet, and counted (shown on a logarithmic scale). Each data point represents the average obtained from three independent experiments.

cells, there appeared to be a reduction in the extent of repair; only $50 \%$ of the lesions were removed from each strand 20 hours after UV treatment. Both cell lines with mutations in $h \mathrm{MSH} 2$ showed some reduction in the extent of repair. A similarly modest reduction in overall nucleotide excision repair has been observed in mutS strains of E. coli (6).

Cell lines harboring mutations in mismatch repair genes show an elevated rate of spontaneous mutation and are continually accumulating genetic alterations at many sites throughout their genomes during growth (19). Consequently, the assignment of any repair deficiency to a mutation at one locus is difficult in the absence of some evidence for genetic correction. Mismatch repair deficiency and microsatellite instability observed in the colon tumor cell line
Fig. 4. TCR in lymphoblastoid cell lines $P 7, P 2$, $P 6$, and P8. Cells were grown in suspension to a density of $1 \times 10^{6}$ cells per dish, pelleted, resuspended at the same density in phosphatebuffered saline, irradiated with $10 \mathrm{~J} / \mathrm{m}^{2}$ of UV light, pelleted, and either lysed immediately or resuspended in growth medium for the specific times shown and then lysed. Samples were then processed as described in Fig. 1.

HCT116, which has a homozygous mutation in the $h M L H 1$ gene (another human homolog of mutL) on chromosome 3 , is corrected by transfer of a normal copy of chromosome 3 (20).

Here, we examined TCR in the parental mutant HCT116 cell line and the chromosome 3-transfer derivative of HCT116 (HCT116 3-6) (Fig. 2). There was no difference in the repair of the two strands of the DHFR gene in HCT116, and the kinetics and extent of repair in both strands resembled that of the repair of the nontranscribed strand of the repair-proficient SW480 cell line (Fig. 1). These results are similar to those obtained with mutL mutant strains of $E$. coli in that TCR was abolished and there was no obvious decrease in overall repair (6). In contrast, introduction of a normal copy of chromosome 3 into the hMLH1 mutant cell lines restored TCR. This is clearly shown by visual comparison of the abundance of full-length restriction fragments in samples treated with $\mathrm{T} 4$ endonuclease $V$ and probed for the two strands 9 and 20 hours after UV treatment. Surprisingly, repair in the nontranscribed strand was reduced relative to the extent of repair observed in the parental HCT116 line. This may be a consequence of the presence of only one functional mismatch repair allele in the corrected cell line.

The HCT116 and LoVo cell lines were somewhat more sensitive to the killing effects of UV irradiation than the repairproficient SW480 cell line (Fig. 3). In addition, the chromosome 3 derivative of HCT116 exhibited increased resistance to UV relative to its parental line, a result that is consistent with the restoration of TCR. Taken together, these results are consistent with studies that have shown a moderate increase in UV sensitivity in $m f d$ (21), $m u t S$, or mutL strains of $E$. coli (6) and in cells from patients with Cockayne's syndrome $(22)$, all of which are deficient in $\operatorname{TCR}(6,23,24)$.

Recently, HNPCC patients were identified with a heterozygous defect in hPMS2. Surprisingly, cells of nontumor origin from these patients exhibited hypermutability in microsatellite DNA (25). In addition, extracts prepared from Epstein-Barr virustransformed lymphoblastoid cells from these patients were virtually devoid of mismatch repair activity. It has been suggested

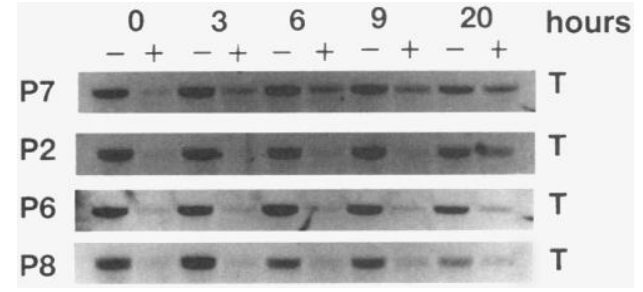

that these specific mutations produce a dominant mutator phenotype. To extend our investigation to human cells of nontumor origin, we investigated TCR in the mutant lymphoblastoid cell lines P7, P2, P6, and P8 (Fig. 4). P7 was derived from a patient with familial adenomatous polyposis, which is not associated with any mismatch repair defect. No alterations in microsatellite repeat length have been detected in this cell line. P2 and P6 are from HNPCC patients and are hPMS2 heterozygotes; both cell lines are deficient in the ability to process substrates containing a single-base mismatch or a dinucleotide insertion. They also exhibit microsatellite instability. P8 is an HNPCC $h \mathrm{MSH} 2$ heterozygote and, unlike $\mathrm{P} 2$ and $\mathrm{P} 6$, is proficient in mismatch repair.

The kinetics and extent of repair in the transcribed strand of the gene encoding DHFR were reduced in both $h P M S 2$ mutant cell lines (Fig. 4). Repair was also reduced in the $\mathrm{hMSH} 2$ heterozygous cell line $\mathrm{P} 8$, but more rapid repair of the transcribed strand was apparent 20 hours after UV treatment. A more extensive examination of mismatch repair-proficient heterozygous lymphoblastoid cell lines is necessary to determine the significance of the reduced nucleotide excision repair observed in the $h \mathrm{MSH} 2$ mutant cell line.

Our results document an association between defects in human mismatch repair genes and the loss of transcription-coupled nucleotide excision repair. All cell lines studied here with defects in TCR have been shown to be virtually devoid of mismatch repair activity in an in vitro assay of cellular extracts. In addition, TCR is restored in a mutant human cell line whose mismatch deficiency has been corrected by chromosome transfer. That the loss of TCR is a direct consequence of mutations in mismatch repair genes is also supported by the observation that TCR is absent in PMS2 ${ }^{-1-}$ and $\mathrm{MSH} 2^{-1-}$ mouse embryonic fibroblast cell lines derived from animals generated by targeted disruption of the respective genes (26-28). Thus, the connection between mismatch repair and nucleotide excision repair documented in $E$. coli extends to mammals. In contrast, no dramatic reduction in TCR was observed in several yeast strains with mutations in mismatch repair genes (29). Yeast also differ from E. coli and 
mammalian cells in that mutations in mismatch repair genes do not result in an increased tolerance to treatment with the alkylating agent $N$-methyl- $N^{\prime}$-nitro- $N$-nitrosoguanidine (MNNG) (30). It is possible that genetic redundancy and the expression levels of different mismatch repair genes influence the biological consequences of a mutation in a mismatch repair gene.

It is thought that an increase in the spontaneous accumulation of mutations that are the result of an inability to process mispairs leads to the development of cancer associated with HNPCC. However, this theory does not explain the unique spectrum of tumors associated with HNPCC (predominantly colon) or the differences in the tumors observed in mismatch repairdefective mice (lymphomas) (26) and HNPCC patients. It is possible that the inactivation of the ability to process mispairs is not the cause of tumorigenesis in HNPCC. Nucleotide excision repair recognizes a wide spectrum of DNA lesions produced by physical and chemical agents present in the environment (31). Furthermore, TCR has been demonstrated for substrates of nucleotide excision repair and base excision repair (32). Although the enhancement of excision repair by transcription may appear subtle, if mutations in human mismatch repair genes abolish many types of TCR, then a reduction in the repair of environmentally induced DNA damage could affect the development of cancer associated with defects in mismatch repair genes.

In addition, a subtle defect in the repair of DNA damage could have a more profound impact on tumorigenesis if it is less likely to be lethal to the cell. Although predisposition to cancer is not associated with Cockayne's syndrome, these patients die on average by 12 years of age (33). In general, tumors associated with HNPCC develop later in a patient's life. This could explain the observation made by Parsons et al. (25) that although there appeared to be widespread mutations in non-neoplastic cells from several different tissues in a subset of HNPCC patients, there was no significant increase in the frequency of tumors. On the basis of these results, they suggested that an increase in spontaneous mutations may not be sufficient for tumorigenesis and exposure to environmental mutagens may have a part in the process.

\section{REFERENCES AND NOTES}

1. J. J. H. Hoeijmakers, Trends Genet. 9, 173 (1993); ibid., p. 211

2. I. Mellon, G. Spivak, P. C. Hanawalt, Cell 51, 241 (1987); J. Venema et al., Mol. Cell. Biol. 8, 4128 (1991).

3. I. Mellon and P. C. Hanawalt, Nature 342, 95 (1989) C. P. Selby and A. Sancar, Science 260, 53 (1993).

4. C. Terleth, C. C. A. van Sluis, P. van de Putte, Nucleic
Acids Res. 17, 4433 (1989); M. J. Smerdon and F. Thoma, Cell 61, 675 (1990); S. A. Leadon and D. A Lawrence, J. Biol. Chem. 267, 23175 (1992); K. S Sweder and P. C. Hanawalt, Proc. Natl. Acad. Sci. U.S.A. 89, 10696 (1992).

5. P. C. Hanawalt, B. A. Donahue, K. S. Sweder, Curr. Biol. 4, 518 (1994).

6. I. Mellon and G. N. Champe, Proc. Natl. Acad. Sci. U.S.A. 93, 1292 (1996).

7. P. Modrich, Annu. Rev. Genet. 25, 229 (1991).

8. R. Fishel et al., Cell 75, 1027 (1993); F. S. Leach et al., ibid., p. 1215; C. E. Bronner et al., Nature 368, 258 (1994); N. Papadopoulos et al., Science 263, 1625 (1994); N. C. Nicolaides et al., Nature 371, 75 (1994).

9. R. D. Kolodner, Trends Biochem. Sci. 20, 397 (1995); T. A. Kunkel, Curr. Biol. 5, 1091 (1995).

10. H. T. Lynch, T. C. Smyrk, P. Watson, S. J. Lanspa, J. F. Lynch, Gastroenterology 104, 1535 (1993).

11. P. Watson and H. T. Lynch, Cancer 71, 677 (1993).

12. R. Parsons et al., Cell 75, 1227 (1993).

13. A. Umar et al. J. Biol. Chem. 269, 14367 (1994).

14. K. Orth et al., Proc. Natl. Acad. Sci. U.S.A. 91, 9495 (1994).

15. A.-L. Borresen et al., Hum. Mol. Genet. 4, 2065 (1995).

16. J. I. Risinger, A. Umar, J. C. Barrett, T. A. Kunkel, J. Biol. Chem. 270, 18183 (1995)

17. I. Mellon and G. N. Champe, unpublished data.

18. J. C. Boyer et al., Cancer Res. 55, 6063 (1995).

19. Y. Ionov, A. Peinado, S. Malkhosyan, D. Shibata, M. Perucho, Nature 363, 558 (1993); L. A. Aaltonen et al., Science 260, 812 (1993); N. P. Bhattacharyya, A. Skandalis, A. Ganesh, J. Groden, M. Meuth, Proc. Natl. Acad. Sci. U.S.A. 91, 6319 (1994).
20. M. Koi et al., Cancer Res. 54, 4308 (1994).

21. A. R. Oller, I. J. Fijalkowska, R. L. Dunn, R. M Schaaper, Proc. Natl. Acad. Sci. U.S.A. 89, 11036 (1992).

22. L. V. Mayne and A. R. Lehmann, Cancer Res. 42, 1493 (1992)

23. J. Venema, L. H. F. Mullenders, A. T. Natarajan, A. A van Zeeland, L. V. Mayne, Proc. Natl. Acad. Sci. U.S.A. 87, 4707 (1990).

24. C. P. Selby, E. M. Witkin, A. Sancar, ibid. 88, 11574 (1991).

25. R. Parsons et al., Science 268, 738 (1995)

26. S. M. Baker et al., Cell 82, 309 (1995).

27. A. H. Reitmair et al., Nature Genet. 11, 64 (1995).

28. I. Mellon et al., unpublished data.

29. K. S. Sweder et al., Genetics, in press.

30. W. Xiao, L. Rathgeber, T. Fontanie, S. Bawa, Carcinogenesis 16, 1933 (1995)

31. R. S. Lloyd and B. Van Houten, in DNA Repair Mechanisms: Impact on Human Diseases and Cancer J.-M. Vos, Ed. (R. G. Landes, Austin, TX, 1995), pp 25-66.

32. S. A. Leadon and P. K. Cooper, Proc. Natl. Acad. Sci. U.S.A. 90, 10499 (1993)

33. M. A. Nance and S. A. Berry, Am. J. Med. Genet. 42 68 (1992).

34. L. Lommel and P. C. Hanawalt, Mol. Cell. Biol. 13, 970 (1993).

35. We thank T. A. Kunkel, A. Umar, R. Parsons, and B. Vogelstein for providing us with cell lines and D. Powell for critical comments on the manuscript. This study was supported by a research grant from $\mathrm{NIH}$ (GM45535-03) to I.M.

6 December 1995; accepted 25 March 1996

\title{
Linkage of Replication to Start by the Cdk Inhibitor Sic1
}

\author{
B. L. Schneider, ${ }^{\star}$ Q. - H. Yang, ${ }^{\star}$ A. B. Futcher
}

In Saccharomyces cerevisiae, three $\mathrm{G}_{1}$ cyclins (CIns) are important for Start, the event committing cells to division. Sic1, an inhibitor of Clb-Cdc28 kinases, became phosphorylated at Start, and this phosphorylation depended on the activity of CIns. Sic1 was subsequently lost, which depended on the activity of CIns and the ubiquitin-conjugating enzyme Cdc34. Inactivation of Sic1 was the only nonredundant essential function of CIns, because a sic 1 deletion rescued the inviability of the $c / n 1 \mathrm{cln} 2 \mathrm{cln} 3$ triple mutant. In sic 1 mutants, DNA replication became uncoupled from budding. Thus, Sic1 may be a substrate of CIn-Cdc28 complexes, and phosphorylation and proteolysis of Sic 1 may regulate commitment to replication at Start.

Before yeast can replicate DNA, they must pass Start, which requires a cyclin-dependent protein kinase composed of a catalytic subunit (Cdc28) and one of three $G_{1}$ cyclins $(\mathrm{Cln} 1,-2$, or -3) (1). After Start, B-type cyclin-Cdc28 kinases such as Clb5-Cdc28 and Clb6-Cdc28 must be activated to allow replication (2). Although Clb5- and Clb6Cdc28 complexes are present in $G_{1}$ phase, they are initially inactive because of inhi-

B. L. Schneider and A. B. Futcher, Post Office Box 100, Cold Spring Harbor Laboratory, Cold Spring Harbor, NY 11724, USA.

Q.-H. Yang, Post Office Box 100, Cold Spring Harbor Laboratory, Cold Spring Harbor, NY 11724, USA, and Graduate Program in Genetics, State University of New York, Stony Brook, NY 11794, USA

*These authors contributed equally to this work. †To whom correspondence should be addressed. Email: futcher@cshl.org bition by the Sic1 protein $(2,3)$. Activation of Clb5- and Clb6-Cdc28 occurs after Sic1 is targeted for proteolysis by the ubiquitin-conjugating enzyme Cdc 34 (2). Thus, a cdc34 mutant arrests with a 1N DNA content because it cannot degrade Sic1, but nevertheless buds, and duplicates its spindle pole body.

It is not known how Start triggers Sic 1 inactivation or how replication is tied to other Start-dependent events such as budding and duplication of the spindle pole body. Is Start a single event that affects multiple pathways, or is Start a collection of events, one of which regulates Sic1 proteolysis and replication?

We asked whether Cln-Cdc28 complexes phosphorylate Sic1, thereby targeting it for proteolysis. Sic1 coprecipitates with 